\title{
New developments in treatment of ovarian carcinoma: focus on trabectedin
}

\author{
This article was published in the following Dove Press journal: \\ Cancer Management and Research \\ 30 September 2010 \\ Number of times this article has been viewed
}

\author{
Philippe A Cassier ${ }^{1}$ \\ Aude Duret ${ }^{*}$ \\ Olivier Trédan' \\ Nicolas Carrabin ${ }^{2}$ \\ Pierre Méeus ${ }^{2}$ \\ Isabelle Treilleux ${ }^{3}$ \\ Jean-Paul Guastalla' \\ Isabelle Ray-Coquard 1,4 \\ 'Département de médecine, \\ ${ }^{2}$ Département de chirurgie, and \\ ${ }^{3}$ Département d'anatomopathologie, \\ Centre Léon Bérard, ${ }^{4}$ EA 4 I 29 SIS \\ Lyon, France \\ *Deceased
}

\begin{abstract}
Trabectedin is a new marine-derived compound that binds the DNA minor groove and interacts with proteins of the DNA repair machinery. Trabectedin has shown promising single-agent activity in pretreated patients with soft tissue sarcoma, and ovarian and breast cancer, and combination with various other chemotherapeutic drugs seems feasible. Toxicities are mainly hematologic and hepatic, with Grade 3-4 neutropenia and thrombocytopenia observed in approximately $50 \%$ and $20 \%$ of patients, respectively, and Grade 3-4 elevation of liver enzymes observed in $35 \%-50 \%$ of patients treated with trabectedin. The recently reported results of a large Phase III trial comparing pegylated liposomal doxorubicin (PLD) alone with a combination of PLD and trabectedin in patients with recurrent ovarian cancer showed improved progression-free survival with the combination of trabectedin and PLD, albeit at the price of increased toxicity. Current research focuses on the identification of predictive factors for patients treated with trabectedin, as well as the development of other combinations.
\end{abstract}

Keywords: chemotherapy, ovarian cancer, combination, drug development, DNA repair

\section{Introduction}

Epithelial ovarian cancer is the leading cause of death from gynecologic cancers in Western countries. ${ }^{1,2}$ Most patients present with advanced disease (ie, Stage III and IV), and are managed with surgical resection followed by platinum-based chemotherapy. ${ }^{3}$ During the past decade, advances in chemotherapy have resulted in improved survival and in more effective treatment of relapsed disease. However, five-year overall survival remains relatively low, at around $30 \%{ }^{4}$

The most important prognostic factors at primary diagnosis are International Federation of Gynecologists and Obstetricians (FIGO) stage and complete resection of disease (microscopic residual disease following primary surgery). The time point of relapse following the completion of chemotherapy defines the category of platinum sensitivity, ie, the longer the interval, the longer the duration of response likely to be achieved by platinum retreatment. Patients whose disease responds to first-line therapy but relapses $\geq 12$ months after completion of initial platinum-based therapy are considered to have platinum-sensitive disease. Patients who relapse 6-12 months after primary therapy have intermediate or partial platinum-sensitive disease. Patients who relapse shortly (<six months) after the completion of primary therapy, are considered to have platinum-resistant disease. Patients who relapse during primary therapy are considered to have platinum-refractory disease.

Chemotherapy retreatment is an important aspect in the overall management of patients with platinum-sensitive relapse of recurrent ovarian cancer. Platinum is
Correspondence: Philippe A Cassier Centre Léon Bérard, 28 rue Laennec, 69008, Lyon, France

Tel +33478782828

Fax +33478787337

Email cassierp@hotmail.com 
the backbone of chemotherapy for patients with advanced ovarian cancer, and carboplatin and paclitaxel have emerged as standard in the first-line setting. This combination is also regarded as a valid option for rechallenge in patients with platinum-sensitive recurrent ovarian cancer. A pooled analysis of three Phase III trials from the Arbeitsgemeinschaft Gynaëkologische Onkologie Studiengruppe Ovarialkarzinom and International Collaborative Ovarian Neoplasm collaborators demonstrated significant improvements in progression-free survival and overall survival in patients with platinum-sensitive recurrent ovarian cancer treated with platinum-paclitaxel versus conventional, mainly singleagent, platinum-based therapies. ${ }^{5}$ However, rechallenge with carboplatin and paclitaxel has been limited by the risk of cumulative peripheral neuropathy. Other carboplatin-based combinations, such as gemcitabine and carboplatin, have been explored with the aim of improving both efficacy and tolerability. Carboplatin and gemcitabine significantly improved progression-free survival versus carboplatin alone in a Phase III trial (hazards ratio [HR] 0.72, $P=0.0031){ }^{6}$ Overall survival, however, was not significantly improved (HR 0.96, $P=0.735$ ), although the trial was not powered to detect a survival difference. Grade 3-4 hematologic toxicities were significantly more frequent in the combination arm. More recently, Pujade-Lauraine et al reported a Phase III trial comparing carboplatin and paclitaxel with carboplatin and pegylated liposomal doxorubicin (PLD) in patients with ovarian carcinoma relapsing more than six months after first- or second-line platinum- and taxane-based therapy. ${ }^{7}$ In this trial, the largest in recurrent ovarian cancer, treatment with carboplatin and PLD was associated with improved progression-free survival (11.3 versus 9.4 months, $P=0.005$ ) and a favorable safety profile.

Treatment options for patients with partial platinumsensitive disease ( six months $\leq$ platinum-free interval $<12$ months) include carboplatin-based doublets (either with paclitaxel or gemcitabine), which achieve progressionfree survival durations of approximately eight months, ${ }^{8}$ and PLD. ${ }^{9}$ In this subset of patients, PLD was shown to be superior to topotecan in terms of both progression-free survival and overall survival, ${ }^{10}$ although it has never been compared "head to head" with a platinum doublet. Overall survival in patients with partial platinum-sensitive disease recurrence is approximately 13-15 months. An emerging strategy in these patients is to "artificially" increase the platinum-free interval by using a nonplatinum-containing regimen upon relapse, with the aim of reversing platinum resistance. ${ }^{11}$
In patients with platinum-resistant or refractory recurrent ovarian cancer, treatment options are limited, and this patient subgroup has a poor prognosis. Agents that can be considered include PLD, topotecan, gemcitabine, paclitaxel, oral etoposide, and vinorelbine. Because the reported response rate for each of these drugs is in the $10 \%-20 \%$ range in patients with platinum-resistant disease, the choice is often driven by the side effect profile and the convenience of administration. ${ }^{12}$ Topotecan and PLD have been more extensively studied in this setting, and seem to provide some benefit in progressionfree survival, although rarely associated with an improvement in overall survival.

\section{Trabectedin: a minor groove alkylator}

Trabectedin (ET743, Yondelis ${ }^{\circledR}$; PharmaMar, Madrid, Spain), a tetrahydroisoquinoline alkaloid, is a natural product derived from the marine tunicate Ecteinascidia turbinate. Trabectedin (ET743) binds to the minor groove of DNA and alkylates guanine at the N2 position, whereas most alkylating agents bind guanine at position $\mathrm{N} 7$ or $\mathrm{O} 6$ in the major groove. Binding of trabectedin has been shown to be DNA sequence-specific, with guanine-cytosine rich triplets more frequently bound. ${ }^{13}$ Covalent binding of trabectedin induces DNA bending towards the major groove and a widening of the DNA minor groove. ${ }^{14}$ Modification of the DNA conformation leads to inhibition of activated transcription, while constitutive transcription seems unaffected. ${ }^{15}$

ET743 has shown potent antitumor activity in preclinical studies both in vitro and in vivo in several solid tumors, including ovarian and breast cancer, melanoma, and sarcoma. ${ }^{16,17}$ These preclinical data have been confirmed in several Phase II trials in soft tissue sarcoma, and breast and ovarian carcinoma. Trabectedin is approved in the European Union and several other countries for the treatment of relapsed soft tissue sarcoma which has progressed despite previous treatment with anthracyclines and ifosfamide, or in those who are unable to receive these agents. It is also approved in the European Union in combination with PLD for the treatment of platinum-sensitive recurrent ovarian cancer. In addition, trabectedin holds orphan drug status for the treatment of advanced recurrent soft tissue sarcoma in the US, Switzerland, and Korea, and for the treatment of advanced recurrent ovarian cancer in the US and Switzerland. Trabectedin is under development for prostate cancer, breast cancer, and pediatric soft tissue sarcoma.

Several reports have underlined the importance of nucleotide-excision repair in the cytotoxicity of ET743, 
and more precisely the cell killing ability of this drug has been linked to transcription-coupled nucleotide-excision repair. ${ }^{13,14,18}$ The DNA bending induced by the binding of trabectedin to the minor groove is detected by the transcriptioncoupled nucleotide-excision repair machinery, which in the repair process makes single-strand breaks on each side of the lesion. ${ }^{13}$ These breaks are then made irreversible by the DNAprotein crosslinking capacities of trabectedin. ${ }^{19}$ Recently Herrero et al ${ }^{18}$ suggested a slightly different model based on their observations in the yeast model, Schizosaccharomyces pompe. In this model, cells deficient for Rad13 (the yeast equivalent to human XPG, an endonuclease of the nucleotideexcision repair system), were resistant to trabectedin, while those with an inactive Rad51 (a protein of the homologous recombination repair pathway, involved in the repair of double-strand breaks) were more sensitive to trabectedin than wild-type cells. Based on these observations, Herrero et al suggested the following sequence: trabectedin binds covalently to the DNA minor groove, the resulting adduct is recognized by the nucleotide-excision repair machinery, and then the recruited Rad13 (XPG) protein binds to DNA and interacts with the minor groove-bound drug by means of an arginine residue located in the $\mathrm{COOH}$ terminus. Other proteins of the nucleotide-excision repair machinery trying to repair the damage are then hijacked, forming larger, more toxic complexes. Lastly, during the $\mathrm{S}$ phase, the aforementioned complexes give rise to double-strand DNA breaks, explaining the sensitivity of cells deficient for homologous recombination repair pathway proteins $(\mathrm{eg}, \operatorname{Rad} 51) .{ }^{18}$

\section{Single-agent trabectedin in advanced ovarian carcinoma}

Three Phase II studies have investigated the activity of trabectedin in patients with recurrent advanced ovarian cancer (Tables 1 and 2). Based on preclinical data showing that trabectedin was active in xenograft models with low sensitivity to cisplatin or paclitaxel, Sessa et $\mathrm{al}^{20}$ reported the results of a Phase II study of trabectedin in patients with ovarian cancer failing platinum- and taxane-based therapy. Fifty-nine patients were enrolled and stratified according to platinum sensitivity, ie, 30 patients with platinum-resistant disease (no change after at least four cycles of platinum or taxane, progressive disease after two cycles, or relapse within an interval of less than six months after discontinuation of chemotherapy) and 29 patients with platinum-sensitive disease (relapse after a progression-free interval of $\geq$ six months after completion of platinum-based chemotherapy). Twenty-two (37\%) patients had received at least two prior
Table I Summary of efficacy of trabectedin as a single agent in relapsed ovarian cancer

\begin{tabular}{|c|c|c|c|c|c|c|}
\hline Study & $\begin{array}{l}\text { PFI } \\
\text { (months) }\end{array}$ & $\mathbf{n}$ & CR & PR & ORR & $\begin{array}{l}\text { Median PFS } \\
\text { (months) }\end{array}$ \\
\hline Sessa & $<6$ months & 30 & 0 & $2(7 \%)$ & $7 \%$ & NR \\
\hline et $\mathrm{al}^{20}$ & $\geq 6$ months & 29 & I (3\%) & $9(31 \%)$ & $34 \%$ & NR \\
\hline Krasner & $<6$ months & 81 & 0 & $5(6 \%)$ & $6 \%$ & 2.0 \\
\hline \multirow[t]{2}{*}{ et $\mathrm{al}^{21}$} & $6-12$ months & 43 & I (2\%) & $9(22 \%)$ & $24 \%$ & 4.0 \\
\hline & $\geq 12$ months & 23 & $3(13 \%)$ & $5(22 \%)$ & $35 \%$ & 5.1 \\
\hline Del & $<6$ months & 7 & 0 & 1 & $14.3 \%$ & NR \\
\hline Campo & $6-12$ months & 48 & NR & NR & $29.9 \%$ & 5.6 \\
\hline et $\mathrm{al}^{22}$ & $\geq 12$ months & 52 & NR & NR & $48.1 \%$ & 10.8 \\
\hline
\end{tabular}

Abbreviations: PFI, platinum-free interval; $\mathrm{CR}$, complete response; PR, partial responses; ORR, overall response rate; NR, not reported.

lines of treatment. Trabectedin was administered as a threehour infusion every three weeks, initially given at the dose of $1650 \mu \mathrm{g} / \mathrm{m}^{2}$ based on the recommended Phase II dose found in Phase I trials. The dose in this study was subsequently decreased to $1500 \mu \mathrm{g} / \mathrm{m}^{2}$, and then to $1300 \mu \mathrm{g} / \mathrm{m}^{2}$, because of toxicity (essentially liver toxicity). Systemic antiemetic prophylaxis with intravenous 5-hydroxytryptamine-3 antagonists and $10 \mathrm{mg}$ of dexamethasone intravenously was mandatory, and patients took $4 \mathrm{mg}$ of dexamethasone bid for prophylaxis against liver toxicity. Fifty-one patients were assessable according to RECIST (Response Evaluation Criteria In Solid Tumors) criteria. The overall response rate in the 23 assessable patients with platinum-sensitive disease was $43.5 \%$, (one complete response lasting 8.7 months and nine partial responses) and an additional nine patients had stable disease. Median time to progression for patients who achieved a partial response was 7.9 months. In the platinumresistant stratum, the overall response rate was $7 \%$, and two of 28 patients achieved a partial response lasting 4.0 and 4.6 months. Stable disease was achieved by eight additional patients $(28.6 \%)$. At the higher dose level of $1650 \mu \mathrm{g} / \mathrm{m}^{2}$ Grade 4 elevation of liver transaminases, asthenia, and nausea and vomiting were seen in $83 \%, 82 \%$, and $50 \%$ of patients. At the $1300 \mu \mathrm{g} / \mathrm{m}^{2}$ dose level, treatment was well tolerated with a transient increase in transaminases and Grade 3-4 neutropenia. Two patients $(3 \%)$ in this study experienced febrile neutropenia (one at the $1650 \mu \mathrm{g} / \mathrm{m}^{2}$ dose level and the other at the $1300 \mu \mathrm{g} / \mathrm{m}^{2}$ dose level). ${ }^{20}$

The results of the second Phase II trial of trabectedin in patients with ovarian carcinoma were reported by Krasner et al. ${ }^{21}$ This study enrolled 147 patients who had received no more than two prior platinum-containing regimens. Trabectedin was administered as a three-hour infusion weekly for three weeks of a four-week cycle at $580 \mu \mathrm{g} / \mathrm{m}^{2}$, after premedication by $10 \mathrm{mg}$ of intravenous dexamethasone. 
Table 2 Summary of the most commonly encountered Grade 3-4 side effects in single-agent trials of trabectedin in patients with ovarian cancer

\begin{tabular}{|c|c|c|c|c|c|c|c|c|c|c|}
\hline Study & Schedule & $\begin{array}{l}\text { Infusion } \\
\text { time } \\
\text { (hours) }\end{array}$ & $\mathbf{n}$ & AST & ALT & Bilirubin & $\begin{array}{l}\text { Neutro- } \\
\text { penia }\end{array}$ & $\begin{array}{l}\text { Thrombo- } \\
\text { cytopenia }\end{array}$ & Fatigue & $\begin{array}{l}\text { Nausea } \\
\text { vomiting }\end{array}$ \\
\hline \multirow[t]{3}{*}{ Sessa et $\mathrm{a}^{20}$} & $1650 \mu \mathrm{g} / \mathrm{m}^{2} / 3$ wks & 3 & 6 & $6(100 \%)^{\mathrm{a}}$ & - & 0 & NA & NA & NA & NA \\
\hline & $1500 \mu \mathrm{g} / \mathrm{m}^{2} / 3$ wks & 3 & 12 & $10(84 \%)^{\mathrm{a}}$ & - & 0 & NA & NA & NA & NA \\
\hline & $1300 \mu \mathrm{g} / \mathrm{m}^{2} / 3$ wks & 3 & 41 & $31(75 \%)^{\mathrm{a}}$ & - & 0 & $17(4 \mid \%)$ & $3(7 \%)$ & $3(7 \%)$ & $2(5 \%)$ \\
\hline $\begin{array}{l}\text { Krasner } \\
\text { et } \mathrm{al}^{21}\end{array}$ & $\begin{array}{l}580 \mu g / \mathrm{m}^{2} / \mathrm{wk} \\
3 / 4 \text { wks }\end{array}$ & 3 & 147 & $4(3 \%)$ & $18(12 \%)$ & 0 & $12(8 \%)$ & $4(3 \%)$ & $8(5 \%)$ & $8(5 \%)$ \\
\hline Del Campo & $1500 \mu \mathrm{g} / \mathrm{m}^{2} / 3$ wks & 24 & 54 & $19(35 \%)$ & $30(56 \%)$ & 0 & $29(54 \%)$ & $4(8 \%)$ & $8(15 \%)$ & $2(4 \%)$ \\
\hline et $\mathrm{a}^{22}$ & $1300 \mu \mathrm{g} / \mathrm{m}^{2} / 3$ wks & 3 & 53 & $10(19 \%)$ & $31(58 \%)$ & I (2\%) & $20(38 \%)$ & $5(10 \%)$ & $4(8 \%)$ & $3(6 \%)$ \\
\hline
\end{tabular}

Note: aPooled data for AST/ALT elevation.

Abbreviations: AST, aspartate transaminase; ALT, alanine transaminase; wk, week.

One hundred and forty-one patients were evaluable by RECIST criteria, ie, 62 in the platinum-sensitive cohort (defined as relapse after a disease-free interval $\geq$ six months from the end of the last platinum-based chemotherapy) and 79 in the platinum-resistant cohort (defined as disease progression $<$ six months from the end of the last platinum-based treatment). The overall response rate (by RECIST) was $29 \%$ in the platinum-sensitive cohort (four complete responses and 14 partial responses), and the median progression-free survival was 5.1 months. In the platinum-resistant cohort, the overall response rate was $6.3 \%$ (five partial responses) and the median progression-free survival was two months. Toxicity was much more manageable than in the European Phase II study, as a result of the weekly schedule and the lower initial dose intensity delivered. Nausea, vomiting, and fatigue were seen in $50 \%-60 \%$ of patients. The most common Grade 3-4 toxicities were elevated alanine transaminases (11\%), neutropenia (6\%), and nausea, vomiting, and fatigue (5\% each).

Del Campo et al reported on a randomized Phase II study comparing two schedules of trabectedin, ie, $1500 \mu \mathrm{g} / \mathrm{m}^{2}$ over 24 hours every three weeks ( $\operatorname{arm} \mathrm{A}$ ) and $1300 \mu \mathrm{g} / \mathrm{m}^{2}$ over three hours every three weeks ( $\operatorname{arm} B$ ), the primary endpoint being the response rate. ${ }^{22}$ Patients received the recommended antiemetic prophylaxis with setron and dexamethasone. One hundred and eight patients were randomized between the two arms, and 107 received treatment. The intent to treat analysis showed comparable response rates between the two arms (38.9 in arm A, 35.8 in arm B, $P=0.8422$ ). Likewise, the progression-free survival was similar in both arms (6.2 months in $\operatorname{arm} \mathrm{A}, 6.8$ months in arm $\mathrm{B}, P=0.3127$ ) suggesting that the two schedules have similar activity. The most common adverse events were nausea, vomiting, and fatigue, in most cases Grade 1 or 2 . Hematologic toxicity was manageable, and mostly consisted of neutropenia and thrombocytopenia. Febrile neutropenia was seen in five patients (5\%), and two patients died of possible drug-related adverse events.

McMeekin et al reported a pooled analysis of three Phase II studies, including 294 patients, in which three different schedules of administration were compared, one with $1300 \mu \mathrm{g} / \mathrm{m}^{2}$ over three hours, one with $1500 \mu \mathrm{g} / \mathrm{m}^{2}$ over 24 hours, both every three weeks, and one with $580 \mu \mathrm{g} / \mathrm{m}^{2}$ weekly, for three weeks of a 28-day cycle. ${ }^{23}$ However, no significant differences in efficacy were seen between the two every three-week schedules, as was seen in patients with sarcoma. ${ }^{24}$ These two schedules were significantly superior to the weekly schedule, with a better response rate (33\% versus $16 \%, P \leq 0.0001)$ and longer median time to progression (5.8 months versus 2.8 months, $P=0.0001$ ).

Overall, these Phase II studies show that trabectedin has single-agent activity in patients with platinum-sensitive relapsed ovarian carcinoma, with a manageable toxicity profile. The activity of trabectedin in platinum-resistant disease seems more disappointing (Table 1), with reported response rates lower than those reported for other agents currently available, such as PLD, topotecan, ${ }^{9}$ or gemcitabine. ${ }^{25,26}$

\section{Trabectedin-based combinations}

Several Phase I trials of trabectedin-based combinations have been reported, and showed that trabectedin could be safely combined with doxorubicin, ${ }^{27,28} \mathrm{PLD},{ }^{29}$ gemcitabine, ${ }^{30}$ taxanes, ${ }^{31,32}$ and capecitabine..$^{33}$

A recently published article has reported on a Phase I trial investigating the combination of trabectedin and cisplatin. ${ }^{28}$ There is a strong preclinical rationale for this combination based on the mechanisms of action of both drugs which target different pathways of DNA repair (nucleotide excision repair for trabectedin and homologous recombination for cisplatin) and 
on synergistic activity against human tumor xenografts. Sessa et al conducted a Phase I trial of trabectedin and cisplatin, both given on days 1 and 8 of a 21 -day cycle. ${ }^{28}$ Trabectedin was given as a three-hour infusion, starting at $300 \mu \mathrm{g} / \mathrm{m}^{2}$ (with $100 \mu \mathrm{g} / \mathrm{m}^{2}$ increments), and cisplatin at a fixed dose of $40 \mathrm{mg} / \mathrm{m}^{2}$. Persistent neutropenia was the most common dose-limiting toxicity in this study, and several patients had not recovered from Grade 3 neutropenia by day 35 . The recommended Phase II dose of trabectedin was $500 \mu \mathrm{g} / \mathrm{m}^{2}$ on days 1 and 8 in pretreated patients and $600 \mu \mathrm{g} / \mathrm{m}^{2}$ on days 1 and 8 in treatment-naive patients (combined with cisplatin $40 \mathrm{mg} / \mathrm{m}^{2}$ on days 1 and 8). Although antitumor activity was seen with this combination, the results were lower than expected, especially in patients with ovarian carcinoma, and the response rate was comparable with that of single-agent trabectedin (with limitations due to the small sample size of $n=13$ ). One of the hypotheses raised by the authors to explain these deceiving results is that the trabectedin dose intensity was insufficient due to prolonged dose delays. ${ }^{28}$ Development of a three-week schedule was therefore suggested. However, it is noteworthy that these findings are in line with a previous Phase I trial of a combination of trabectedin and carboplatin where hematologic toxicity precluded a dose increase of trabectedin beyond $800 \mu \mathrm{g} / \mathrm{m}^{2}$ every three weeks and carboplatin beyond an area under the concentration-time curve (AUC) of $4 \mathrm{mg} / \mathrm{mL} / \mathrm{min}^{34}$

Other interesting candidates for combination with trabectedin in patients with ovarian cancer include gemcitabine, PLD, and the taxanes. Data on these combinations are summarized in Table 3.

Messersmith et al conducted a Phase I trial exploring the combination of trabectedin and gemcitabine. ${ }^{30}$ Both drugs were administered on days 1,8 , and 15 of a 28-day cycle. Two dose levels were planned for gemcitabine (800 and $\left.1000 \mathrm{mg} / \mathrm{m}^{2}\right)$ and five were planned for trabectedin $(300$, $400,475,535$, and $580 \mu \mathrm{g} / \mathrm{m}^{2}$ ). Fifteen patients were enrolled, of whom five had sarcomas, three had non-small-cell lung cancer, two had colorectal cancer, and two had renal cell carcinoma. All patients but one were pretreated with chemotherapy and 12 patients had received at least two prior regimens. This study was terminated early because of an unacceptable frequency of dose adjustments due to hepatic toxicity. Patients received a median of two (range 1-10) treatment cycles. The dose-escalation scheme was stopped at level 3 (trabectedin $400 \mu \mathrm{g} / \mathrm{m}^{2}$ and gemcitabine $1000 \mathrm{mg} / \mathrm{m}^{2}$ ) where four of six patients required dose hold/cycle delay. Overall cycle delays and dose holds were required in 11 (of 15) patients, in most cases during the two first cycles and most often related to liver toxicity. Dose reductions were required for trabectedin in four patients and gemcitabine in six patients. Dose-limiting toxicity was defined as any of the following during the first cycle: Grade 4 neutropenia (absolute neutrophil count $<500 / \mathrm{mL}$ ) for $>$ five days; febrile neutropenia (absolute neutrophil count $<500 / \mathrm{mL}$ with fever [body temperature $38.5^{\circ} \mathrm{C}$ ] or sepsis); thrombocytopenia (platelets $<25,000 / \mathrm{mL}$ ); any Grade 3 nonhematologic toxicity (except nausea/vomiting and Grade 3 transaminitis lasting $<$ one week); or delay of continuation of therapy $>$ three weeks. Dose reductions were not considered as doselimiting toxicities. No dose-limiting toxicities were seen in any of the cohorts. The most frequently reported Grade 3 or 4 adverse event was alanine transaminase increase (33\%). Although the study was terminated without reaching the maximum tolerated dose, toxicity appeared potentially manageable without evidence of a significant pharmacokinetic interaction with this combination. No objective response was noted, but two patients in this study had stable disease for more than six months. The recommended dose for future trials investigating this combination was trabectedin $400 \mu \mathrm{g} / \mathrm{m}^{2}$ combined with gemcitabine $1000 \mathrm{mg} / \mathrm{m}^{2}$ weekly for three weeks every four weeks.

von Mehren et al conducted a Phase I study to assess the maximum tolerated dose, safety, and potential pharmacokinetic interactions of trabectedin in combination with PLD. ${ }^{29}$ Thirty-six patients with normal liver function, prior doxorubicin exposure $<250 \mathrm{mg} / \mathrm{m}^{2}$, and normal cardiac function were enrolled. A broad range of advanced malignancies was represented, the most common being sarcoma $(n=16)$, ovarian cancer $(n=4)$, and pancreatic cancer $(n=2)$. Twenty-seven patients $(75 \%)$ were pretreated with chemotherapy, with a median of three prior regimens. PLD was administered at the dose of $30 \mathrm{mg} / \mathrm{m}^{2}$ with a one-hour infusion, and followed immediately by one of six trabectedin doses (400, 600, 750, 900, 1100, and $1300 \mu \mathrm{g} / \mathrm{m}^{2}$ ) infused over three hours and repeated every 21 days. All patients received dexamethasone $4 \mathrm{mg} /$ day orally on the day before chemotherapy and on days 2 and 3 of each cycle, as well as $20 \mathrm{mg}$ intravenously on day 1 . Dose-limiting toxicity was defined as the following during cycle 1: an absolute neutrophil count $<500 / \mathrm{mL}$ for $>$ five days or with fever or sepsis; platelet count $<25,000 /$ $\mathrm{mL}$; any Grade 3 or 4 nonhematologic toxicity (except for nausea/vomiting despite appropriate antiemetic treatment or Grade 3 transaminase elevations lasting $<$ one week); or a delay of therapy for $>$ three weeks. The median number of cycles was four. The maximum tolerated dose was PLD $30 \mathrm{mg} / \mathrm{m}^{2}+$ trabectedin $1100 \mu \mathrm{g} / \mathrm{m}^{2}$. Dose-limiting toxicities occurred in two patients in the $1300 \mu \mathrm{g} / \mathrm{m}^{2}$ cohort during 
Table 3 Summary of data on trabectedin-based combination of potential interest in ovarian cancer

\begin{tabular}{|c|c|c|c|c|c|c|}
\hline Combination & Reference & Schedule & $\begin{array}{l}\text { Recommended } \\
\text { Phase II dose }\end{array}$ & $\begin{array}{l}\text { Dose-limiting } \\
\text { toxicity }\end{array}$ & $\begin{array}{l}\text { Efficacy } \\
\text { in ovarian } \\
\text { cancer patients }\end{array}$ & Comments \\
\hline Trabectedin & \multirow[t]{2}{*}{27} & $\begin{array}{l}\text { Days } I \text { and } 8 \\
\text { every } 21 \text { days }\end{array}$ & $500-600 \mu \mathrm{g} / \mathrm{m}^{2}$ & \multirow[t]{2}{*}{$\begin{array}{l}\text { Prolonged } \\
\text { neutropenia }\end{array}$} & $\begin{array}{l}\text { Four of } 13 \\
\text { patients (31\%) }\end{array}$ & \multirow{2}{*}{$\begin{array}{l}\text { Deceiving } \\
\text { efficacy-wise } \\
\text { and toxic }\end{array}$} \\
\hline Cisplatin & & $\begin{array}{l}\text { Days I and } 8 \\
\text { every } 2 \text { I days }\end{array}$ & $40 \mathrm{mg} / \mathrm{m}^{2}$ & & $\begin{array}{l}\text { with OC } \\
\text { had a PR }\end{array}$ & \\
\hline Trabectedin & \multirow[t]{2}{*}{29} & $\begin{array}{l}\text { Days I, } 8 \\
\text { and I } 5 \text { every } \\
28 \text { days }\end{array}$ & $400 \mu g / \mathrm{m}^{2}$ & \multirow[t]{2}{*}{ None } & \multirow[t]{2}{*}{ NR } & \\
\hline Gemcitabine & & $\begin{array}{l}\text { Days I, } 8 \\
\text { and } 15 \text { every } \\
28 \text { days }\end{array}$ & $1000 \mathrm{mg} / \mathrm{m}^{2}$ & & & \\
\hline Trabectedin & \multirow[t]{2}{*}{28} & $\begin{array}{l}\text { Day I every } \\
21 \text { days }\end{array}$ & $1 \mathrm{I} 00 \mu \mathrm{g} / \mathrm{m}^{2}$ & \multirow{2}{*}{$\begin{array}{l}\text { Grade } 3-4 \\
\text { transaminitis } \\
\text { lasting }>7 \text { days }\end{array}$} & \multirow{2}{*}{$\begin{array}{l}\text { One patient with } \\
\text { PPC had a PR } \\
\text { and } 2 \text { of } 4 \text { patients } \\
\text { with OC has SD }\end{array}$} & $\begin{array}{l}\text { A subsequent } \\
\text { phase III trial in }\end{array}$ \\
\hline PLD & & $\begin{array}{l}\text { Day I every } \\
21 \text { days }\end{array}$ & $30 \mathrm{mg} / \mathrm{m}^{2}$ & & & $\begin{array}{l}\text { patients with ROC } \\
\text { showed improved } \\
\text { RR and PFS compared } \\
\text { with PLD alone }\end{array}$ \\
\hline Trabectedin & \multirow[t]{2}{*}{30} & $\begin{array}{l}\text { Day I every } \\
21 \text { days }\end{array}$ & $\mathrm{I} 100 \mu \mathrm{g} / \mathrm{m}^{2}$ & \multirow{2}{*}{$\begin{array}{l}\text { Grade } 4 \text { neutropenia } \\
\text { and/or febrile } \\
\text { neutropenia before } \\
\text { primary prophylaxis } \\
\text { with filgrastim. } \\
\text { Grade } 3 \text { fatigue. }\end{array}$} & \multirow[t]{2}{*}{ NR } & $\begin{array}{l}\text { A subsequent phase II } \\
\text { trial in patients with }\end{array}$ \\
\hline Docetaxel & & $\begin{array}{l}\text { Day I every } \\
21 \text { days }\end{array}$ & $60 \mathrm{mg} / \mathrm{m}^{2}$ & & & $\begin{array}{l}\text { ROC showed a RR, } \\
\text { PFS and OS of } 30 \% \text {, } \\
4.4 \text { months and } \\
12.5 \text { months } \\
\text { respectively }\end{array}$ \\
\hline Trabectedin & 31 & $\begin{array}{l}\text { Day } 2 \text { every } \\
14 \text { days }\end{array}$ & $650 \mu \mathrm{g} / \mathrm{m}^{2}$ & $\begin{array}{l}\text { Grade } 4 \text { neutropenia } \\
\text { lasting } 5 \text { days or }\end{array}$ & $\begin{array}{l}\text { One patient } \\
\text { with } \mathrm{OC} \text { has }\end{array}$ & \\
\hline Paclitaxel & & $\begin{array}{l}\text { Day I every } \\
14 \text { days }\end{array}$ & $120 \mathrm{mg} / \mathrm{m}^{2}$ & $\begin{array}{l}\text { more, dose } \\
\text { delays beyond } 8 \text { days }\end{array}$ & PD (no response) & \\
\hline
\end{tabular}

Abbreviations: PLD, pegylated liposomal doxorubicin; OC, ovarian cancer; ROC, relapsed ovarian cancer; PR, partial response; NR, not reported; RR, response rate; PFS, progression-free survival; OS, overall survival; PD, progressive disease; SD, stable disease.

cycle 1 , consisting of Grade 3 or 4 transaminase elevations lasting $>$ seven days. The most frequent Grade 3 or 4 drugrelated events were alanine transaminase elevations $(31 \%)$ and neutropenia (31\%). Transaminase elevations resolved without specific intervention and were successfully managed with dose reductions. Post-treatment liver biopsies were carried out in eight patients who had elevations in liver function tests, and nonalcoholic steatohepatitis was present in seven of eight biopsies. Six patients had an asymptomatic reduction of left ventricular ejection fraction of $\geq 20 \%$ versus baseline. Only one of these six patients had received a prior anthracycline-based regimen, although all six had a cumulative exposure to anthracyclines of $\geq 300 \mathrm{mg} / \mathrm{m}^{2}$ (range 365-690 $\mathrm{mg} / \mathrm{m}^{2}$ ) when noted to have a change in the left ventricular ejection fraction. Finally, one complete response and five partial responses (overall response rate 16.7\%) were seen and 14 patients had stable disease. The majority of responses occurred in the $1100 \mu \mathrm{g} / \mathrm{m}^{2}$ and the $1300 \mu \mathrm{g} / \mathrm{m}^{2}$ cohorts. Overall, these data show that trabectedin combined with PLD is feasible with encouraging activity. The regimen comprising PLD $30 \mathrm{mg} / \mathrm{m}^{2}$ plus trabectedin $1100 \mu \mathrm{g} / \mathrm{m}^{2}$ was selected for a Phase III trial comparing PLD alone with PLD plus trabectedin in patients with advanced ovarian cancer failing one prior platinum-based regimen.

von Mehren et al reported the results of a Phase I trial of docetaxel $60 \mathrm{mg} / \mathrm{m}^{2}$ combined with trabectedin as a three-hour infusion on day one of a three-week cycle. ${ }^{31} \mathrm{Six}$ dose levels $\left(400 \mu \mathrm{g} / \mathrm{m}^{2}\right.$ through to $1300 \mu \mathrm{g} / \mathrm{m}^{2}$ ) and two independent cohorts, ie, "restricted" ( $\leq$ one prior regimen) and "unrestricted" (no limits as to the number of previous regimens) were planned. Thirty-four patients were enrolled, 10 of whom had sarcoma. Five patients developed doselimiting toxicity at the $600 \mu \mathrm{g} / \mathrm{m}^{2}$ dose level, ie, Grade IV neutropenia and/or febrile neutropenia requiring institution of prophylactic filgrastim. After institution of filgrastim, only one dose-limiting toxicity (fatigue) was observed at the $1300 \mu \mathrm{g} / \mathrm{m}^{2}$ dose level. The most frequent Grade 1-2 adverse events were fatigue (68\%), nausea (58\%), and neutropenia (53\%). Preliminary data suggest activity for this combination in patients with advanced cancer, with one patient achieving 
a complete response and 17 maintaining prolonged stable disease. A subsequent Phase II trial in patients with recurrent ovarian cancer used doses of $60 \mathrm{mg} / \mathrm{m}^{2}$ for docetaxel and $1100 \mu \mathrm{g} / \mathrm{m}^{2}$ of trabectedin given every three weeks. In the preliminary report of this trial, the response rate was $30 \%$, and the median progression-free survival and overall survival were 4.4 months and 12.5 months, respectively. ${ }^{35}$

In their Phase I study, Chu et al administered escalating doses of paclitaxel $\left(80-120 \mathrm{mg} / \mathrm{m}^{2}\right)$ over one hour on day 1 and trabectedin $\left(525-775 \mu \mathrm{g} / \mathrm{m}^{2}\right)$ as a three-hour infusion on day 2 every two weeks. ${ }^{32}$ Twenty-nine patients were enrolled, including 23 patients with soft tissue sarcoma, and 27 patients were evaluable. Two doses were planned for paclitaxel $\left(80 \mathrm{mg} / \mathrm{m}^{2}\right.$ or $\left.120 \mathrm{mg} / \mathrm{m}^{2}\right)$ and four doses for trabectedin $(525$, 580,650 , or $775 \mu \mathrm{g} / \mathrm{m}^{2}$ ), and five schedules were tested. There were four dose-limiting toxicities due to neutropenia delaying therapy for more than one week, two of which occurred on paclitaxel $120 \mathrm{mg} / \mathrm{m}^{2}+$ trabectedin $775 \mu \mathrm{g} / \mathrm{m}^{2}$. Therefore, the recommended dose was paclitaxel $120 \mathrm{mg} / \mathrm{m}^{2}+$ trabectedin $650 \mu \mathrm{g} / \mathrm{m}^{2}$. The most common toxicities were neutropenia (24\%), nausea (51\%), vomiting (24\%), transaminitis (23\%), myalgia (24\%), and alopecia (20\%). Evidence of antitumor activity and clinical benefit was seen, with one patient who had a primitive neuroectodermal tumor showing an ongoing complete response at $19+$ months, one patient with breast cancer (prior paclitaxel failure) having an unconfirmed partial response, and eight patients having stable disease for more than three months.

\section{Trabectedin-PLD combination in relapsed ovarian carcinoma}

Based on the activity of both PLD and trabectedin in patients with relapsed ovarian carcinoma, together with a favorable safety profile described in Phase I investigations, a Phase III trial comparing a combination of PLD and trabectedin with PLD alone in patients with recurrent ovarian cancer was initiated. Six hundred and seventy-two patients progressing after initial response to first-line platinum-based therapy and with measurable disease were randomized to a combination of PLD $30 \mathrm{mg} / \mathrm{m}^{2}$ over 60 minutes and trabectedin $1100 \mu \mathrm{g} / \mathrm{m}^{2}$ over three hours every 21 days (PLD + T, with $10 \mathrm{mg}$ intravenous dexamethasone 30 minutes prior to trabectedin infusion) or standard PLD $50 \mathrm{mg} / \mathrm{m}^{2}$ once every four weeks. Patients experiencing disease progression during platinum-based frontline therapy were excluded. ${ }^{36}$ Progression-free survival was the primary study endpoint and was assessed by independent radiologic review. Baseline characteristics were comparable between arms, ie, median age was 57 years, 421 patients
$(63 \%)$ had platinum-sensitive disease (platinum-free interval for more than six months). The median number of cycles was five for PLD and six for PLD + T. Median progression-free survival for the combination arm was 7.3 months $(95 \%$ CI 5.9-7.9) and 5.8 months (95\% CI 5.5-7.1) for single-agent PLD $(\mathrm{HR}=0.79, P=0.019)$. For patients with platinum-sensitive disease (platinum-free interval more than six months), the median progression-free survival was 9.2 months $(95 \% \mathrm{CI}$ 7.4-11.1) for the combination arm versus 7.5 months $(95 \%$ CI 7.0-9.2) for PLD alone (HR 0.73, $P=0.017$ ). Objective response rate for all patients was $28 \%$ versus $19 \%(P=0.008)$ and $35 \%$ versus $23 \%(P=0.0042)$ for patients with platinumsensitive disease. In the platinum-resistant subgroup, there was no benefit in progression-free survival (4.0 versus 3.7 months for PLD $+\mathrm{T}$ and PLD, respectively) nor in response rate (overall response rate $16 \%$ versus $15 \%$ for PLD $+\mathrm{T}$ and PLD, respectively). There was no overall survival difference between the two arms, ie, 20.5 months for PLD + T versus 19.4 months for PLD alone (HR 0.85, $P=0.15$ ). However, follow-up was insufficient at the time of reporting. Sixteen percent of patients in the combination arm and $10 \%$ in the single-agent PLD arm discontinued treatment because of adverse events. Grade 3 and Grade 4 adverse events included neutropenia (63\% versus $22 \%$ ), elevated alanine transaminase (31\% versus $1 \%)$, and hand-foot syndrome ( $4 \%$ versus $20 \%$ ) for PLD + T versus PLD alone, respectively. On the basis of these results, the authors concluded the superior efficacy the PLD + T combination, which also demonstrates competitive efficacy compared with previously described platinum-based combinations in patients with platinum-sensitive relapsed ovarian cancer.

Despite these conclusions, the FDA denied approval for the combination of trabectedin and PLD in patients with relapsed ovarian carcinoma. One of the reasons was that the FDA panel felt that the six-week benefit in progression-free survival shown in this trial did not justify approval of the drug. Progression-free survival has not been proven to be a valid surrogate for overall survival in patients with relapsed ovarian cancer, and the increment itself is relatively low given the added toxicity. Furthermore, although PLD is an option in patients with relapsed platinum-sensitive disease, platinumbased therapy may be regarded as the preferred treatment in this patient subgroup. Therefore, given the fact that this study included a majority of patients with platinum-sensitive disease, the validity of the comparator may be questioned. Another point of discussion is the lack of benefit in patients with platinum-resistant disease, although this is in line with previous data showing that trabectedin has little efficacy in this patient subgroup. ${ }^{20-22}$ Finally, there was an increase in 
the rate of nonfatal congestive heart failure-related events in the trabectedin group ( six events for PLD $+\mathrm{T}$ versus one for PLD alone). ${ }^{36}$

Interestingly, a subgroup analysis of this study, reported at the 2010 ASCO meeting, suggested that patients with partial platinum-sensitive disease may benefit the most from this combination. ${ }^{37}$ Indeed, 214 patients in this trial had partial platinum-sensitive disease. In this subgroup, the median progression-free survival was 7.4 months for patients treated in the combination arm (T + PLD) versus 5.5 months for patients treated with PLD alone. Furthermore, this benefit translated into an overall survival advantage of 3.5 months (20.7 versus $17.2, P=0.009)$. Two comments can be made on these results. First, because there was no crossover in this study, one cannot rule out that giving sequential single-agent PLD followed by trabectedin at progression may be as or even more effective than the combination. Second, we still need more follow-up to assess overall survival in the whole cohort.

In another subgroup analysis of this trial, investigators sought to identify predictive factors for patients receiving trabectedin. ${ }^{38}$ This study focused on proteins of the nucleotide-excision repair and homologous recombination repair pathways because these pathways are important for trabectedin activity in vitro. The markers studies included ERCC1, XPG (both part of the nucleotide-excision repair machinery), and BRCA1 (homologous recombination repair pathway), and their expression was studied using real-time polymerase chain reaction on prechemotherapy tumor blocks. Patients with low BRCA1 mRNA levels had significantly longer overall survival $(P=0.0297)$ and progression-free survival $(P=0.0427)$ than those with high BRCA1 levels, thereby confirming the prognostic value of BRCA1 expression in patients with ovarian carcinoma. ${ }^{39} \mathrm{~A}$ trend $(P=0.0765)$ for longer overall survival (but not progression-free survival) was found for patients with high ERCC1 expression levels. No significant differences in progression-free survival or overall survival emerged for low or high XPD expression levels. No significant differences in progression-free survival or overall survival were observed with the combined expression of BRCA1 and ERCC1. Caveats of these analyses include low numbers of patients with samples available and/or of adequate quality (139 of 672 patients, 20\%), prior platinum-based therapy in all patients (and $80 \%$ prior taxanes) which might have modified the tumor RNA expression levels.

\section{Other new agents in ovarian cancer}

Several agents are currently in development in ovarian cancer, and can be grouped into three classes, ie, antiangiogenic agents, cell surface-targeted agents, and poly-adenosine triphosphate (ADP) ribose polymerase inhibitor.

Bevacizumab has shown promising results in several Phase II trials, and the Gynecologic Oncology Group GOG218 Phase III trial was recently reported at the 2010 ASCO meeting, showing improved progressionfree survival for patients receiving first-line carboplatinpaclitaxel and bevacizumab, with bevacizumab maintenance therapy. Interestingly, the progression-free survival in the chemotherapy and bevacizumab without maintenance bevacizumab arm was not significantly different from that of the standard arm (carboplatin-paclitaxel alone). This trial therefore raises the question as to whether bevacizumab should be given as a maintenance therapy only, or whether it really needs to be combined in the initial chemotherapy regimen. Furthermore, the improvement in progression-free survival is limited, especially given that maintenance bevacizumab was given every three weeks for 16 cycles (approximately 11 months), and there is currently no overall survival advantage for patients receiving bevacizumab (insufficient follow-up). Therefore, it seems reasonable to wait for the overall survival data to mature, as well as data from other randomized trials (ICON7 trial), before we incorporate bevacizumab as part of standard practice.

Several antiangiogenic tyrosine kinase inhibitors (TKIs) are currently under active investigation in the treatment of advanced ovarian cancer. Cediranib, an oral TKI of vascular endothelial growth factor receptor (VEGFR)-1, VEGFR-2, VEGFR-3, and c-kit, showed interesting single-agent activity in a recently published Phase II trial in patients with relapsed ovarian carcinoma. ${ }^{40}$ BIBF1120, a TKI targeting the VEGF, the platelet-derived growth factor, and the fibroblast growth factor receptor, has shown promising activity as maintenance therapy in a randomized Phase II trial. ${ }^{41}$ Pazopanib, another TKI targeting the VEGF and platelet-derived growth factor receptor, has shown some activity in patients with biochemical relapse of ovarian cancer. ${ }^{42}$ Both of these agents are currently being evaluated in Phase III trials, either in combination (BIBF1120) or as maintenance therapy (pazopanib). ${ }^{4}$

Cell surface targets in ovarian carcinoma include CA-125 and epithelial cell adhesion molecule. However, the current role of the relevant agents (oregomovab, abagomovab, and catumaxomab) in the management of patients with advanced ovarian cancer remains unclear, owing to the lack of a specific trial.

The most recent class of drug developed for patients with advanced ovarian cancer includes the poly-(ADP-ribose)polymerase (PARP) inhibitors. This class of compound 
targets PARPs, which are DNA repair enzymes. Preclinical experiments have shown synthetic lethality in cells deficient in BRCA 1 or BCRA $2 .{ }^{43,44}$ A single-agent Phase I trial showed interesting activity in tumors from BRCA 1 or BRCA 2 mutation carriers, with a favorable toxicity profile. ${ }^{45}$ Gelmon et al reported a Phase II trial in triplenegative breast and high-grade serous ovarian carcinoma demonstrating significant activity of single-agent olaparib in non-BRCA-mutated patients with advanced high-grade ovarian carcinoma. ${ }^{46}$ However, an analysis of the expansion cohort of the Phase I study of olaparib in BRCA mutation carriers showed a correlation between response and duration of the platinum-free interval, suggesting that PARPs may not be as active in patients with platinum-resistant disease. ${ }^{47}$ PARP inhibitors can also be combined with standard chemotherapy, most notably with DNA-damaging agents, with which they are most likely to be synergistic. Only Phase I trials have been reported to date for patients with ovarian carcinoma.

\section{Conclusion}

Trabectedin, a new marine-derived compound, has shown interesting activity in patients with platinum-sensitive relapsed ovarian carcinoma. However, several agents are currently approved for this indication, including paclitaxel, gemcitabine, and PLD. The standard of care in this setting remains the combination of carboplatin and paclitaxel, and a recent Phase III study showed improved progression-free survival and overall survival with weekly paclitaxel coupled with carboplatin for patients with platinum-sensitive recurrent ovarian cancer. ${ }^{48}$

When combined with PLD, trabectedin improved progression-free survival over PLD alone, although no overall survival advantage has yet emerged. ${ }^{36}$ Furthermore, the progression-free survival benefit is numerically small (six weeks) and comes at the price of a significant increase in toxicity, although somewhat different from those seen with platinum or platinum-taxane regimens which are standard for this indication. Another drawback of this study is that singleagent PLD cannot be considered as standard in patients with platinum-sensitive relapsed ovarian cancer. Based on these observations, the use of trabectedin in the management of patients with platinum-sensitive disease cannot be clearly defined, and more studies are needed. However, recent data indicate that patients with partial platinum-sensitive disease benefit from the combination of trabectedin and PLD compared with PLD alone, with superior progression-free survival and overall survival for the combination. ${ }^{37}$

\section{Disclosure}

Dr Philippe A Cassier has had travel expenses covered by PharmaMar; Dr Isabelle Ray-Coquard and Dr Jean-Paul Guastalla have both received honoraria from PharmaMar.

\section{References}

1. Jemal A, Siegel R, Ward E, Hao Y, Xu J, Thun MJ. Cancer statistics, 2009. CA Cancer J Clin. 2009;59:225-249.

2. Guerin S, Doyon F, Hill C. The frequency of cancer in France in 2006, mortality trends since 1950, incidence trends since 1980 and analysis of the discrepancies between these trends. Bull Cancer. 2009;96:51-57. French.

3. Cannistra SA. Cancer of the ovary. N Engl J Med. 2004;351: 2519-2529.

4. Harter P, Hilpert F, Mahner S, Heitz F, Pfisterer J, du Bois A. Systemic therapy in recurrent ovarian cancer: Current treatment options and new drugs. Expert Rev Anticancer Ther. 2010;10:81-88.

5. Parmar MK, Ledermann JA, Colombo N, et al. Paclitaxel plus platinumbased chemotherapy versus conventional platinum-based chemotherapy in women with relapsed ovarian cancer: The ICON4/AGO-OVAR-2.2 trial. Lancet. 2003;361:2099-2106.

6. Pfisterer J, Plante M, Vergote I, et al. Gemcitabine plus carboplatin compared with carboplatin in patients with platinum-sensitive recurrent ovarian cancer: An Intergroup trial of the AGO-OVAR, the NCIC CTG, and the EORTC GCG. J Clin Oncol. 2006;24: 4699-4707.

7. Pujade-Lauraine E, Wagner U, Avall-Lundqvist E, et al. Pegylated liposomal doxorubicin and carboplatin compared with paclitaxel and carboplatin for patients with platinum-sensitive ovarian cancer in late relapse. J Clin Oncol. 2010;28:3323-3329.

8. Pfisterer J, Vergote I, du BA, Eisenhauer E. Combination therapy with gemcitabine and carboplatin in recurrent ovarian cancer. Int J Gynecol Cancer. 2005;15 Suppl 1:36-41.

9. Gordon AN, Fleagle JT, Guthrie D, Parkin DE, Gore ME, Lacave AJ. Recurrent epithelial ovarian carcinoma: A randomized Phase III study of pegylated liposomal doxorubicin versus topotecan. J Clin Oncol. 2001;19:3312-3322.

10. Gordon AN, Tonda M, Sun S, Rackoff W. Long-term survival advantage for women treated with pegylated liposomal doxorubicin compared with topotecan in a Phase 3 randomized study of recurrent and refractory epithelial ovarian cancer. Gynecol Oncol. 2004; 95:1-8.

11. Colombo N, Gore M. Treatment of recurrent ovarian cancer relapsing 6-12 months post platinum-based chemotherapy. Crit Rev Oncol Hematol. 2007;64:129-138.

12. Cannistra SA. Evaluating new regimens in recurrent ovarian cancer: How much evidence is good enough? J Clin Oncol. 2010; 28:3101-103.

13. David-Cordonnier MH, Gajate C, Olmea O, et al. DNA and non-DNA targets in the mechanism of action of the antitumor drug trabectedin. Chem Biol. 2005;12:1201-1210.

14. Takebayashi Y, Pourquier P, Zimonjic DB, et al. Antiproliferative activity of ecteinascidin 743 is dependent upon transcription-coupled nucleotide-excision repair. Nat Med. 2001;7:961-966.

15. Friedman D, Hu Z, Kolb EA, Gorfajn B, Scotto KW. Ecteinascidin743 inhibits activated but not constitutive transcription. Cancer Res. 2002;62:3377-3381.

16. Valoti G, Nicoletti MI, Pellegrino A, et al. Ecteinascidin-743, a new marine natural product with potent antitumor activity on human ovarian carcinoma xenografts. Clin Cancer Res. 1998;4:1977-1983.

17. Hendriks HR, Fiebig HH, Giavazzi R, Langdon SP, Jimeno JM, Faircloth GT. High antitumour activity of ET743 against human tumour xenografts from melanoma, non-small-cell lung and ovarian cancer. Ann Oncol. 1999;10:1233-1240. 
18. Herrero AB, Martin-Castellanos C, Marco E, Gago F, Moreno S. Crosstalk between nucleotide excision and homologous recombination DNA repair pathways in the mechanism of action of antitumor trabectedin. Cancer Res. 2006;66:8155-8162.

19. Takebayashi Y, Goldwasser F, Urasaki Y, Kohlhagen G, Pommier Y. Ecteinascidin 743 induces protein-linked DNA breaks in human colon carcinoma HCT116 cells and is cytotoxic independently of topoisomerase I expression. Clin Cancer Res. 2001;7:185-191.

20. Sessa C, de Braud F, Perotti A, et al. Trabectedin for women with ovarian carcinoma after treatment with platinum and taxanes fails. J Clin Oncol. 2005;20:1867-1874.

21. Krasner CN, McMeekin DS, Chan S, et al. A Phase II study of trabectedin single agent in patients with recurrent ovarian cancer previously treated with platinum-based regimens. Br J Cancer. 2007;97:1618-1624.

22. Del Campo JM, Roszak A, Bidzinski M, et al. Phase II randomized study of trabectedin given as two different every 3 weeks dose schedules $\left(1.5 \mathrm{mg} / \mathrm{m}^{2} 24 \mathrm{~h}\right.$ or $\left.1.3 \mathrm{mg} / \mathrm{m}^{2} 3 \mathrm{~h}\right)$ to patients with relapsed, platinum-sensitive, advanced ovarian cancer. Ann Oncol. 2009;20:1794-1802.

23. McMeekin S, del Campo JM, Colombo N, et al. Trabectedin (T) in relapsed advanced ovarian cancer (ROC): A pooled analysis of three phase II studies. ASCO Meeting Abstracts 2007 Jun 20;25(18 Suppl):5579.

24. Morgan JA, Le Cesne A, Chawla S, et al. Randomized Phase II study of trabectedin in patients with liposarcoma and leiomyosarcoma (L-sarcomas) after failure of prior anthracylines (A) and ifosfamide (I). [abstract] J Clin Oncol. 2007;25 Suppl 18S:10060.

25. Mutch DG, Orlando M, Goss T, et al. Randomized Phase III trial of gemcitabine compared with pegylated liposomal doxorubicin in patients with platinum-resistant ovarian cancer. J Clin Oncol. 2007;25:2811-2818.

26. Ferrandina G, Ludovisi M, Lorusso D, et al. Phase III trial of gemcitabine compared with pegylated liposomal doxorubicin in progressive or recurrent ovarian cancer. J Clin Oncol. 2008;20;26:890-896.

27. Blay JY, von Mehren M, Samuels BL, et al. Phase I combination study of trabectedin and doxorubicin in patients with soft-tissue sarcoma. Clin Cancer Res. 2008;14:6656-6662.

28. Sessa C, Cresta S, Noberasco C, et al. Phase I clinical and pharmacokinetic study of trabectedin and cisplatin in solid tumours. Eur J Cancer. 2009;45:2116-2122.

29. von Mehren M, Schilder RJ, Cheng JD, et al. A Phase I study of the safety and pharmacokinetics of trabectedin in combination with pegylated liposomal doxorubicin in patients with advanced malignancies. Ann Oncol. 2008;19:1802-1809.

30. Messersmith WA, Jimeno A, Ettinger D, et al. Phase I trial of weekly trabectedin (ET-743) and gemcitabine in patients with advanced solid tumors. Cancer Chemother Pharmacol. 2008;63:181-188.

31. von Mehren M, Buck D, Temmer E, Elsayed YA, Cohen RB. Phase I study of trabectedin (T) in combination with docetaxel (D) in patients with advanced malignancies. J Clin Oncol. 2006;24 Suppl 18S:2068

32. Chu Q, Mita A, Forouzesh B, et al. Phase I and pharmacokinetic study of sequential paclitaxel and trabectedin every 2 weeks in patients with advanced solid tumors. Clin Cancer Res. 2010;16:2656-2665.

33. Gore L, Rivera E, Lavallee K, et al. Phase I combination study of trabectedin $(\mathrm{T})$ and capecitabine $(\mathrm{C})$ in patients with advanced malignancies. J Clin Oncol. 2006;24 Suppl 18S:2079.

Cancer Management and Research

\section{Publish your work in this journal}

Cancer Management and Research is an international, peer-reviewed open access journal focusing on cancer research and the optimal use of preventative and integrated treatment interventions to achieve improved outcomes, enhanced survival and quality of life for the cancer patient. The journal welcomes original research, clinical \& epidemiological

Submit your manuscript here: http://www.dovepress.com/cancer-management-and-research-journal
34. Vidal L, Garcia-Martin M, Tan S, et al. Phase I combination study of trabectedin and carboplatin in patients with advanced solid tumors. Ann Oncol. 2010;15 Suppl 3:iii102-1.

35. Monk BJ, Sill M, Walker JL, et al. Activity of docetaxel plus trabectedin in recurrent or persistent ovarian and primary peritoneal cancer: A Phase II study of the Gynecologic Oncology Group (GOG). J Clin Oncol. 2010; 28 Suppl 15:5046.

36. Monk BJ, Herzog TJ, Kaye SB, et al. Trabectedin plus pegylated liposomal doxorubicin in recurrent ovarian cancer. J Clin Oncol. 2010; 28:3107-3114.

37. Poveda A, Tjulandin S, Kong B, et al. Extending platinum-free interval (PFI) in partially platinum-sensitive (PPS) patients (pts) with recurrent ovarian cancer (ROC) treated with trabectedin ( $\mathrm{Tr}$ ) plus pegylated liposomal doxorubicin ( $\mathrm{Tr}+\mathrm{PLD}$ ) versus PLD alone: Results from a PPS cohort of a phase III study. J Clin Oncol. 2010;28 Suppl 15:5012.

38. Poveda A, Kaye SB, Herzog T, et al. Correlation of RNA expression of DNA repair genes with clinical outcomes of advanced ovarian cancer (OC) pts treated with pegylated liposomal doxorubicin (PLD) vs trabectedin (T) + PLD in the ET743-OVA-301 clinical trial. Eur J Cancer Suppl. 2009;7:451.

39. Weberpals J, Garbuio K, O'Brien A, et al. The DNA repair proteins BRCA1 and ERCC1 as predictive markers in sporadic ovarian cancer. Int J Cancer. 2009; 124:806-815.

40. Matulonis UA, Berlin S, Ivy P, et al. Cediranib, an oral inhibitor of vascular endothelial growth factor receptor kinases, is an active drug in recurrent epithelial ovarian, fallopian tube, and peritoneal cancer. J Clin Oncol. 2009;27:5601-5606.

41. Ledermann JA, Rustin GJ, Hackshaw A, et al. A randomized Phase II placebo-controlled trial using maintenance therapy to evaluate the vascular targeting agent BIBF 1120 following treatment of relapsed ovarian cancer (OC). J Clin Oncol. 2009;27 Suppl 15S:5501.

42. Friedlander M, Hancock KC, Benigno B, et al. Pazopanib (GW786034) is active in women with advanced epithelial ovarian, fallopian tube and peritoneal cancers: Initial results of a Phase II study. J Clin Oncol. 2007;25 Suppl 18S:5561.

43. Bryant HE, Schultz N, Thomas HD, et al. Specific killing of BRCA2deficient tumours with inhibitors of poly(ADP-ribose) polymerase. Nature. 2005;434:913-917.

44. Farmer H, McCabe N, Lord CJ, et al. Targeting the DNA repair defect in BRCA mutant cells as a therapeutic strategy. Nature. 2005;434:917-921.

45. Fong PC, Boss DS, Yap TA, et al. Inhibition of poly(ADP-ribose) polymerase in tumors from BRCA mutation carriers. $N$ Engl J Med. 2009;361:123-134.

46. Gelmon KA, Hirte HW, Robidoux A, et al. Can we define tumors that will respond to PARP inhibitors? A Phase II correlative study of olaparib in advanced serous ovarian cancer and triple-negative breast cancer. J Clin Oncol. 2010;28 Suppl 15S:3002.

47. Fong PC, Yap TA, Boss DS, et al. Poly (ADP)-ribose polymerase inhibition: Frequent durable responses in BRCA carrier ovarian cancer correlating with platinum-free interval. J Clin Oncol. 2010;28:2512-2519.

48. Katsumata N, Yasuda M, Takahashi F, et al. Dose-dense paclitaxel once a week in combination with carboplatin every 3 weeks for advanced ovarian cancer: A phase 3, open-label, randomised controlled trial. Lancet. 2009;374:1331-1338.

studies, reviews \& evaluations, guidelines, expert opinion \& commentary, case reports \& extended reports. The manuscript management system is completely online and includes a very quick and fair peerreview system, which is all easy to use. Visit http://www.dovepress.com/ testimonials.php to read real quotes from published authors. 